\title{
Review Paper on Inter Story Isolation System
}

\author{
Pranav Thakur ${ }^{1}$, Susanta Kumar Sethy ${ }^{2}$, Mukesh Kumar Dubey ${ }^{3}$ \\ ${ }^{I}$ Student M. Tech Structure, ${ }^{2,3}$ Assistant Professor, Civil Engineering department, University of Petroleum and \\ Energy Studies, Dehradun, India
}

\begin{abstract}
In higher seismic zones construction of high rise building with normal earthquake resistant design, it is necessary to provide their structural frame sufficient rigidity vertically and horizontally, make sure rigidity and strength in the plane. In base isolated building their upper structure experienced less seismic forces due to decoupling of superstructure to ground motion and is able to sustain concentration of rigidity and strength. Inter story isolation is evolved after the limitations of base isolation to meet the requirements of architectural, functional and cost consideration of structure. This system allows freedom for different structural planning of upper and lower level of isolation layer. In this paper seismic performance of buildings is measured using isolation at different levels. The different parameters like base shear, time period, story drift and story displacement are compared. Inter story isolation system also introduce high rise buildings by which the potential for new architectural planning and structural system is used for different purposes in building.
\end{abstract}

Keywords: Base Isolation, Inter story isolation, Elastomeric Isolators, Seismic Performance, Base shear, Time period.

\section{INTRODUCTION}

Important structures like hospitals, nuclear power plants and other structures need to constructed seismic resistant in high earthquake prone areas. Traditional earthquake design does not give much rigidity too structures during fatal earthquakes. There are also some factors that came into play for which control of structural response is required. These factors are i) Higher safety purpose ii) Improve flexibility iii) Economic concerns iv) Stringent performance levels. So in 1980s the research in this field has developed several methods which increased the seismic performance of structures. There are different vibration absorption methods like active control, passive control, hybrid control and semi active control. Base isolation is a technique which work as a passive vibration control system and it will decouple the superstructure from its substructure resting on a shaking ground and thus protecting the structures integrity. This technique is commonly used in countries like japan where high magnitude earthquakes occur usually. In India base isolation is used in some important structures which is need to preserved during earthquakes

\section{INTER-STORY ISOLATION}

Inter isolation system is come into use after the limitations of base isolation. Base isolation is a method that is used to protect the structure against seismic forces. In general buildings with base isolation the upper structure which is supported in isolation layer have less affected by seismic forces and able to resist concentration of rigidity and strength. Thus it allows the freedom for structural and architectural planning above the isolation layer. Thus intermediate isolation at high rise building allows different structural planning above and lower level of isolation layer. The structure above isolation layer have high seismic resistance and a mass damper helps to decrease the seismic response in lower structure and improve the seismic response as a whole structure. Now days high rise buildings is build for different purposes with respect to different levels of building and to make them seismic resistant we will provide intermediate isolation layer. This will help the building for different architectural planning at below and above level of isolation layer to serve different purposes. Cost reduction is also playing a role in intermediate isolation system as properties of isolation layer is dependent on axial load of columns. By providing isolation layer at inter story level axial load is get decreased for given isolator and it will reduce the cost.

\section{ELASTOMERIC BEARING}

The elastomer is a elastic polymer which is made up of material like silicone rubber, butyl rubber and fluorosilicate rubber. The material selection of elastomer is dependent on ultimate loading, sensitivity of environment and internal properties. The properties of elastomeric isolators can meet specific applications of modulus of elasticity, internal dampening. Its homogeneous nature allows for compact forms. The key design parameters for 
isolator is configuration, loading, spring rate (shear bulk, geometry), ultimate strength, internal damping and maximum displacement. It is made up of rubber layers and steel shins as a cover with lead. An elastomeric bearing consists of alternating layers of rubber and steel shims bonded together. Elastomeric bearings are more helpful for lateral loads as compared to vertical loads. In this isolators use either natural rubber or synthetic rubber (such as neoprene), which have little inherent damping, usually $2 \%$ to $3 \%$ of critical viscous damping. High damping and Low damping type are two types.

\section{LITRATURE REVIEW}

In this paper author describes the properties of isolation layer which is used in middle story of building and also introduce the potential for new architecture system proposed through this system. [1] This paper shows the response properties of high rise buildings and by using middle storey isolation degree of freedom of architectural planning can be expanded and the seismic performance increased [1]

In this paper a G+14 multi storey building is modelled with a middle storey isolation system by using isolators and dampers. He performed non-linear time history analysis to analyze the performance of building. [2] It results that building with middle storey isolation structural system had no restriction on the connection with $b / w$ the ground surface and building which permit the different vertical structural system. This effect improved the seismic performance of entire building remarkably.[2]

In this paper author examined two existing building with inter isolation system using modal and time history analysis. It clearly show the vibration characteristics of mid-story isolation and how they affect the structural response under seismic input. [3] The results shows that inter isolation system provide complex design as compared to base isolation. The upper structure above from isolation level is less rigid as compared to lower level is not ideal for inter isolation system.

\section{APPLICATION OF INTER STOREY ISOLATION SYSTEM}

Inter storey isolation system technique is used these days after architectural, functional and cost consideration of structure comes into play. Retrofitting is a prominent application of inter isolation system. These are the some examples of structures in which inter isolation system is used.
"Iidabashi First Building, First Hills Iidabashi" in which the optimum structure and framing forms for each use were stacked vertically (Murakami et al, 1998 )

This is a 14-story compound building comprising residential, office, and commercial facilities.

It has different architectural planning above and below isolation layer. It is consist of SRC (steel \& reinforced concrete) RC (reinforced concrete) and steel materials. Laminated rubber isolator is used in isolation system.
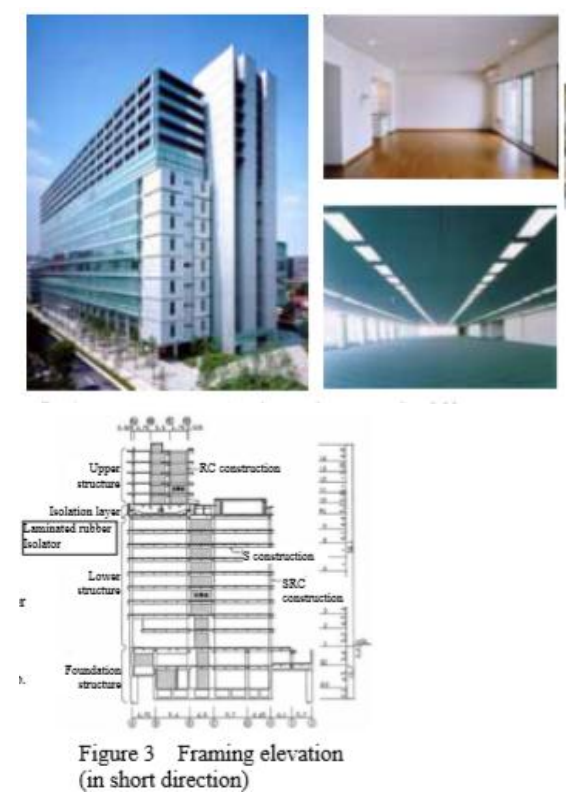

Fig (a)

\section{Musashino City Disaster Prevention and Safety Center}

In this example a two storey steel building is expanded to five storey to form a high seismic performance disaster prevention center. With the help of inter mediate isolation the expanded part will not damage by major earthquake. There are 8 pieces of natural rubber, 12 pieces of sliding bearings and 8 pieces of steel rod dampers.

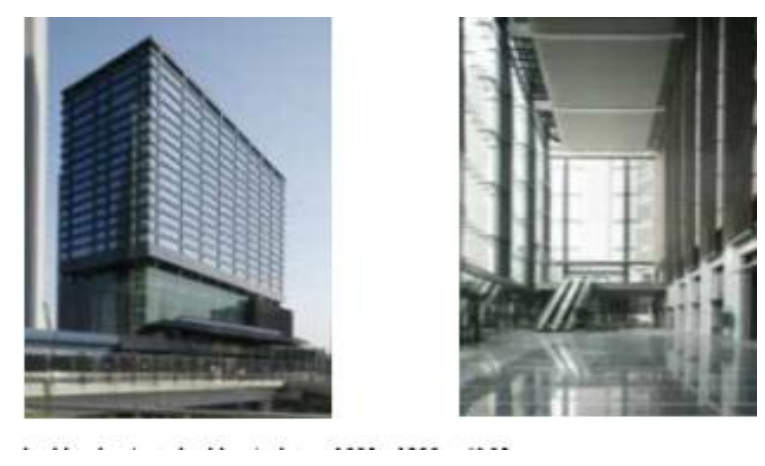




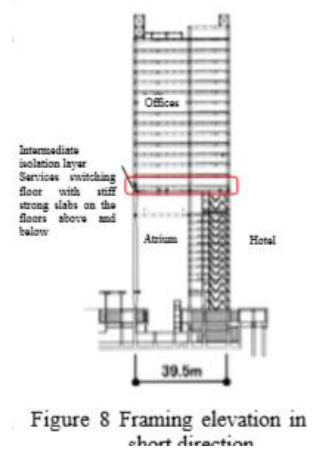

Fig (b)

\section{Koraku 2-Chome, Bunkyo-ku (Tokyo)}

It is a multi-functional building with 14 stories in which isolation layer is provided at intermediate level. There are offices at lower level and apartments at upper level. Laminated rubber bearing is used as isolator at inter-mediate level.

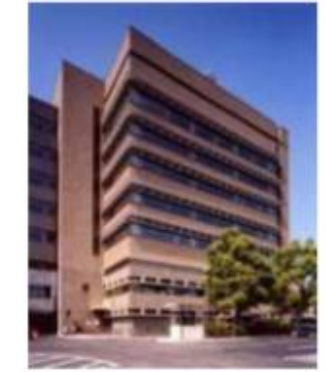

Photo 4 Building external view

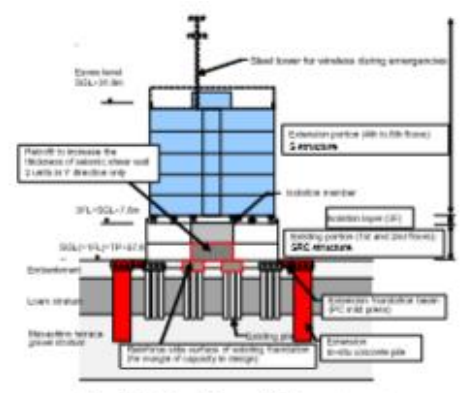

Fig. 11 Outline of the structure
Fig (c)

\section{CONCLUSION}

The time period is increased in high rise building with base isolation as compared to fixed base and inter storey isolation which reduce the transfer of lateral force at the time of earthquake. The building with irregular shapes have more time period using base isolation. Base shear is reduced by using elastomeric isolators over the conventional structure. The result shows that the response of structure can be reduced by using elastomeric isolators. By using inter isolation the stiffness of isolator is reduced due to less axial load and it will result in reduction of cost of elastomeric isolator. Inter mediate isolation also result in increasing the stiffness of a multifunctional building and it will allow the use of new architectural and structural system in building.

\section{REFFRENCES}

[1] Y. Tsuneki, S. Torii, . K. Murakami and T. Sueoka, "MIDDLE-STORY ISOLATED STRUCTURAL SYSTEM OF HIGH-RISE BUILDING," in World Conference on Earthquake Engineering , Beijing, 2008.

[2] E. mele and D. Faiella, "Inter-Story Isolation Systems (IIS) For Tall Buildings: Design Considerations," CTBUH Journal, no. II, 2018.

[3] K. MURAKAMI1, . H. KITAMURA, . H. OZAKI and . T. TERAMOTO, "DESIGN AND ANALYSIS OF A BUILDING WITH THE MIDDLE-STORY ISOLATION STRUCTURAL SYSTEM," in World Conference on Earthquake Engineering, 2000.

[4] A. J. Thoriya and . M. A. Dhankot, "PASSIVE CONTROL OF STRUCTURES USING SLIDING ISOLATORS AT INTERMEDIATE FLOOR LEVELS," IJRET: International Journal of Research in Engineering and Technology, vol. 03, no. 04, 2004. 